\title{
Spatial scales of benthic and pelagic producer biomass in a coastal upwelling ecosystem
}

\author{
Bernardo R. Broitman ${ }^{1,2, *}$, Brian P. Kinlan ${ }^{1}$ \\ ${ }^{1}$ Department of Ecology, Evolution and Marine Biology and Marine Science Institute, University of California, \\ Santa Barbara, California 93106-9610, USA
}

${ }^{2}$ Present address: National Center for Ecological Analysis and Synthesis, University of California, Santa Barbara, 735 State Street, Suite 300, Santa Barbara, California 93101-3351, USA

\begin{abstract}
We studied the spatial structure of benthic and pelagic primary producer biomass over a large region on the west coast of North America, between Baja California del Sur, Mexico $\left(27^{\circ} \mathrm{N}\right)$, and Oregon, USA $\left(42^{\circ} \mathrm{N}\right)$. The distribution of benthic primary producer biomass was determined from repeated aerial surveys of shallow subtidal kelp stands, and pelagic primary producer biomass, from the long-term average of nearshore chlorophyll a concentrations from the Sea-viewing Wide Field-of-view Sensor (SeaWiFS). Spatial analyses showed a striking match between the patch scales of kelp stands and chlorophyll a concentrations, with a characteristic length scale of $\sim 180 \mathrm{~km}$. Crosscorrelation analysis revealed that kelp and phytoplankton biomass were negatively correlated from 0 to $150 \mathrm{~km}$ lag distances in the equatorward direction and 0 to $30 \mathrm{~km}$ in the poleward direction. Positive correlations at distances longer than the patch scale detected in the spatial analysis indicated that patches of benthic and pelagic biomass were offset in space. A spatial analysis of coastline features and long-term average coastal sea surface temperature anomalies from AVHRR (Advanced Very High Resolution Radiometer) suggested that the spatial structure of benthic and pelagic primary producer biomass was associated with topographic forcing of coastal upwelling. Our results suggest that shoreline geomorphology has strong effects on coastal ecosystems, by altering the spatial distribution of primary producer biomass over characteristic spatial scales.
\end{abstract}

KEY WORDS: Coastal primary production · Spatial distribution · Coastal topography · Upwelling · Chlorophyll $a \cdot$ Macrocystis pyrifera $\cdot$ SeaWiFS $\cdot$ AVHRR

\section{INTRODUCTION}

Elevated primary production in coastal upwelling ecosystems supports some of the most productive coastal regions of the world (Longhurst 1998). Thus, understanding processes controlling the spatial distribution of primary production has large implications for coastal conservation and management. The key process determining primary production in these eastern boundary ecosystems is wind-driven upwelling of cold, nutrient-rich waters from below the euphotic layer (Brink 1983, Longhurst 1998). The delivery of nutrients to coastal waters sustains the production of a large biomass in the benthic zone by sessile macroalgae (Bustamante et al. 1995, Broitman et al. 2001) and in the pelagic zone by phytoplankton (Dugdale \& Wilkerson 1989, Thomas et al. 2001).

Satellite-borne instruments and other remote sensing platforms have become increasingly available and currently allow access to biological and physical information over unprecedented spatial and temporal scales. Remote sensing of spatial variability of primary producer biomass has led to the identification of several mechanisms driving pelagic ecosystem structure through the upwelling of deep, nutrient-rich water into oligotrophic surface layers (Siegel 2001). Some of the main mechanisms identified for open ocean waters are mesoscale eddies (McGillicuddy et al. 1998, Doney et al. 2003) and planetary Rossby waves (Cipollini et al. 2001, Uz et al. 2001), which fuel large phytoplankton 
blooms in otherwise unproductive surface waters. As such, examination of spatial patterns of primary production in the open ocean has led to the identification of physical forcing mechanisms that affect the distribution of primary production in open ocean waters. The complexity of the coastal environment, particularly in the extreme nearshore $(<20 \mathrm{~km}$ from shore), has limited our ability to scale-up observations and experiments on local processes determining the abundance of primary producers to the regional scales in which coastal ecosystems are interconnected and managed.

A starting point for the scaling-up of ecological predictions is a rigorous characterization of the dominant spatial scales of the coastal ecosystem. Once these scales are identified, predictions can be tested in order to identify the mechanisms driving the distribution of primary production, including circulation and key ecological processes, such as propagule dispersal and nutrient supply. The processes that determine the distribution and abundance of benthic and pelagic primary producers differ in fundamental ways that may lead to differences in their pattern of distribution. Nearshore oceanography determines the distributions of both nutrients and phytoplankton, via upwelling, retention, and advection of water masses. Phytoplankton thus interact with the environment in a moving parcel of water (i.e. a Lagrangian frame). Benthic macroalgae, in contrast, experience resource inputs in a time-integrated fashion at a fixed location in space (i.e. a Eulerian frame). Thus, the biomass of phytoplankton observed nearshore may correspond to sustained accumulation from distant inputs, but the density of benthic macroalgae is a direct reflection of local production. Patchiness in the distribution of rocky reefs and competition for space with other organisms creates a rich potential for complex ecological feedbacks modulating the spatial distribution of benthic primary producers (Menge et al. 1997).

A coarse method of prediction of coastal ecological patterns has been based on the distribution of mesoscale topographic features, such as capes and headlands (Brink 1983). Topographic features generate spatial patterns of population and community structure in their vicinity (Ebert \& Russell 1988, Wing et al. 1995). The spatial patterns in benthic ecology observed around these features have been attributed to the effect of topography on nearshore circulation. Offshore flow and the upwelling of cold, nutrient-rich waters is often locked to topographic features and associated bottom topography at small and large spatial scales (Strub et al. 1991, Roughan et al. 2005b). In contrast, onshore flow and more complex surface circulation patterns are common elsewhere along the coastline (Graham \& Largier 1997, Largier 2002,
Roughan et al. 2005a). Topographic features modify alongshore oceanographic conditions via the interaction of flow and/or wind fields with coastal geomorphology (Gan \& Allen 2002, Largier 2002, Castelao \& Barth 2005, Roughan et al. 2005b). As a consequence, coastal topography may provide a proxy for the formation of ecological patterns in space through differences in alongshore circulation processes delivering nutrients to the coastal ecosystem. Although the association between topography and alongshore distribution patterns of primary production has long been recognized (Abbott \& Barksdale 1991), a formal spatial analysis testing the coupling of spatial pattern to such physical forcing mechanisms in the nearshore has not been attempted previously.

Quantitative, spatially intensive characterizations of alongshore distribution of primary producer biomass have been rare, due largely to the complex spatiotemporal patterns and paucity of oceanographic observations in the nearshore. Using a combination of novel statistical techniques and remote-sensing datasets, we attempt to fill that gap. The objective of the present study is to provide a rigorous assessment of the spatial scales of variation in benthic and pelagic standing stock of primary producers along the coast of western North America (WNA) and to test their association to several proxies of physical forcing of surface circulation. We present the first quantitative indication that a strong pattern with characteristic spatial scales in alongshore distribution of both benthic and pelagic primary producer biomass may result from the interaction of flow field with topography in a coastal upwelling ecosystem.

\section{MATERIALS AND METHODS}

Datasets and validation. We examined the spatial structure of benthic and pelagic primary producer biomass across the coastal upwelling region of WNA, between Baja California del Sur, Mexico $\left(27^{\circ} \mathrm{N}\right)$, and Oregon, USA $\left(42^{\circ} \mathrm{N}_{i}\right.$ Fig. 1). Spatial patterns of pelagic primary producer (phytoplankton) standing stock were examined using the long-term mean biomass $\left(\mathrm{mg} \mathrm{m}^{-3}\right)$ of satellite-based Sea-viewing Wide Field-of-view Sensor (SeaWiFS) coastal surface chlorophyll a (chl a) concentration. The mean was calculated from $4 \mathrm{yr}$ (1997 to 2001) of $8 \mathrm{~d}$ SeaWiFS composites, with a latitudinal resolution of $0.036^{\circ}(4 \mathrm{~km})$ averaged over $12 \mathrm{~km}$ cross-shelf transects perpendicular to the coast (Fig. 1A). We used the long-term mean of the $12 \mathrm{~km}$ data to reduce the noise and anomalies inherent in coastal ocean color data and to reliably identify areas characterized by consistently high or low phytoplankton biomass. 


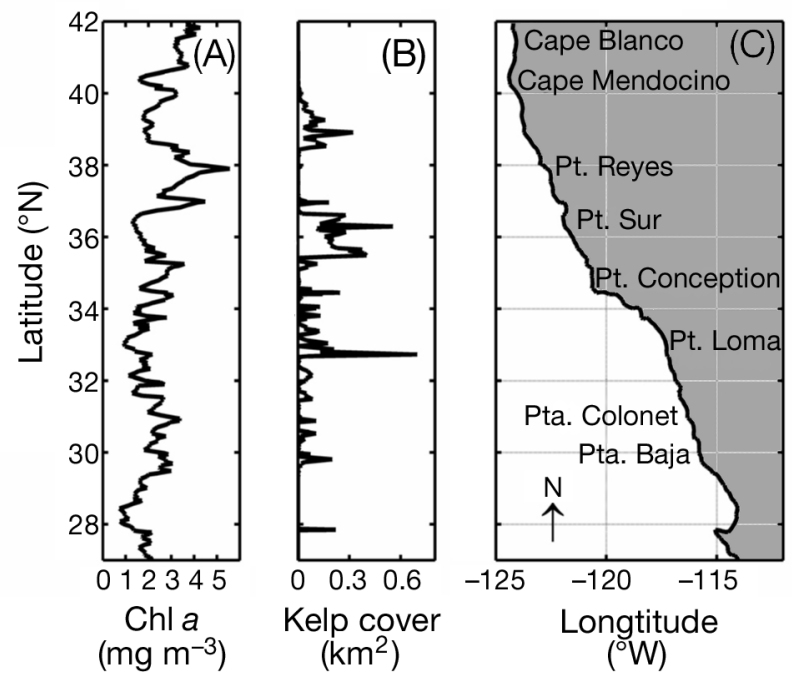

Fig. 1. (A) Long-term mean of SeaWiFS coastal chlorophyll a (chl a) concentration within $12 \mathrm{~km}$ of shore. (B) Multi-survey composite of kelp surface canopy cover measured from aerial infrared photography (California; 1989, 1999, 2002) and Landsat-7 imagery (Mexico; 2000, 2001). (C) Coastline of continental western North America, between 27 and $42^{\circ} \mathrm{N}$ (offshore islands have been removed)

The $12 \mathrm{~km}$ SeaWiFS long-term mean was derived from a subsample of data for WNA presented by Thomas et al. (2001). To examine the validity of the spatial pattern in the chl a spatial series, we compared satellite estimates to averages of in situ measurements of chl $a$ at 38 intertidal, mooring, and pier sites in our study region maintained by the Partnership for Interdisciplinary Studies of Coastal Oceans (PISCO; C. Blanchette, P. Drake, F. Chan \& A. Kirincich pers. comm.) and the Network for Environmental Observations of the Coastal Ocean (NEOCO; J. Largier \& M. McManus pers. comm.). The agreement between SeaWiFS and in situ data was good, despite the very nearshore location and point-resolution of the ground data $\left(\mathrm{r}^{2}=0.45, \mathrm{p}<0.001\right.$; Fig. $\left.2 \mathrm{~A}\right)$. The correlation coefficient for this relationship was similar to previous groundtruthing results from the Santa Barbara Channel region $\left(\mathrm{r}^{2}=0.53\right.$; Otero \& Siegel 2004). The nearshore long-term mean also agreed well with the long-term mean derived from cross-shelf transects that extended $100 \mathrm{~km}$ offshore $\left(\mathrm{r}^{2}=0.68, \mathrm{p}<0.001\right.$; Fig. 2B). As expected in coastal waters, variance is higher in the nearshore chl a relative to the $100 \mathrm{~km}$ cross-shelf pattern (Fig. 2B). Although phytoplankton concentrations in the study region show strong seasonal variations (Kahru \& Mitchell 2001), the spatial pattern in the seasonal distributions is extremely consistent (spring-summer vs. fall-winter, $r=0.9635, p<0.001$ ). Together, these validation exercises give us confidence that the long-term mean of the remotely sensed chl $a$
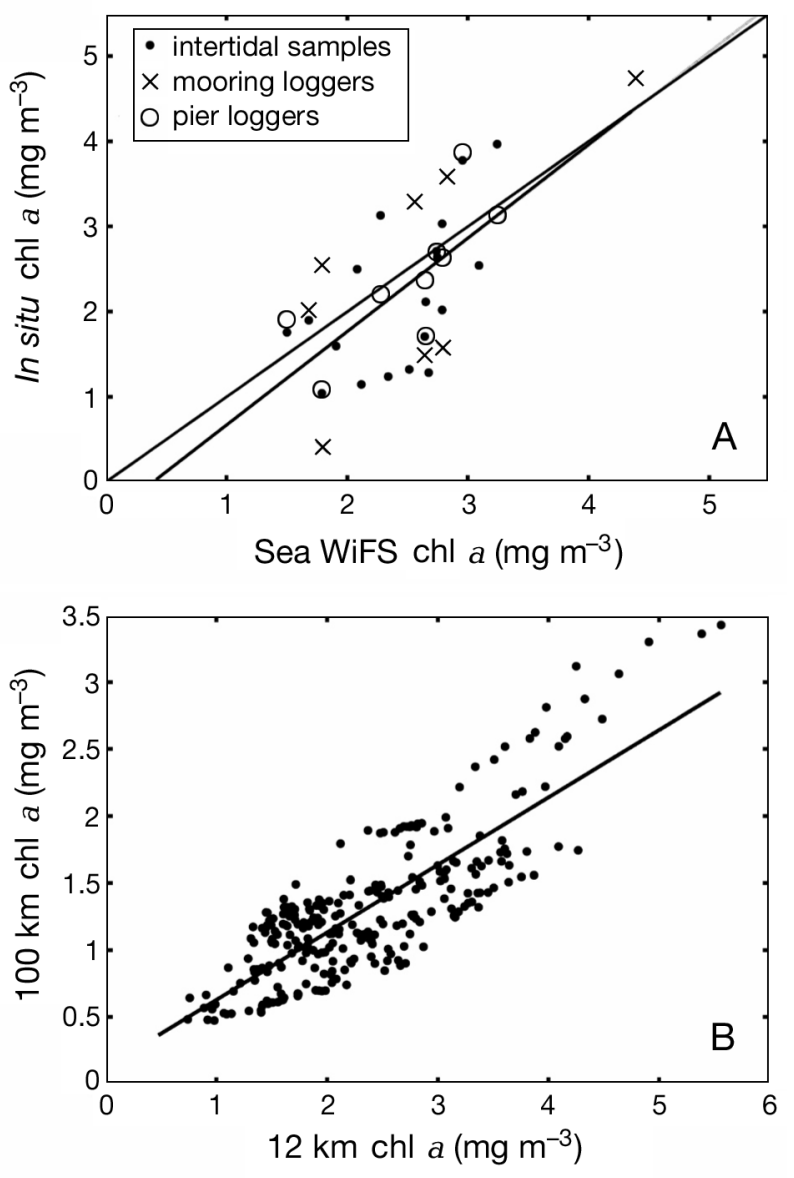

Fig. 2. (A) Linear regression of long-term mean SeaWiFS chl a concentration averaged over the first $12 \mathrm{~km}$ cross-shelf versus long-term averages obtained in the nearshore from fluorometers mounted on moorings and piers ( $<1 \mathrm{~km}$ from shore), and repeated water samples at intertidal sites. Agreement with the satellite data is good $\left(\mathrm{r}^{2}=0.45, \mathrm{p}<0.001\right)$; the $1: 1$ line is plotted for reference. (B) Linear regression of long-term SeaWiFS chl a concentration averaged over the first $12 \mathrm{~km}$ cross-shelf versus $100 \mathrm{~km}$ cross-shelf averages. Agreement between both estimates of chl a biomass is good $\left(\mathrm{r}^{2}=0.68\right.$,

$$
\mathrm{p}<0.001)
$$

biomass is not driven by problems with SeaWiFS calibration in the nearshore and that it represents a reasonable estimate of the spatial distribution of chl a across the region examined.

The spatial pattern of benthic primary producer standing stock was examined using a combination of 3 datasets: (1) the surface canopy cover of benthic kelps from aerial infrared photographic surveys of the entire California coast in 1989, 1999, and 2002 (32.5 to $42^{\circ} \mathrm{N}, 2 \mathrm{~m}$ resolution; California Department of Fish and Game); (2) the surface canopy cover of benthic kelps from Landsat-7 Thematic Mapper imagery of Baja California del Norte, Mexico, in April to May 2000 and 2001 (27 to $32.5^{\circ} \mathrm{N}, 30 \mathrm{~m}$ resolution; M. Merrified \& M. Jian, Nature Conservancy California Program, 
pers. comm.); and (3) monthly aerial estimates of giant kelp canopy biomass from Punta Eugenia, Baja California del Sur, Mexico, to Monterey, California, USA, spanning the period from 1989 to 2002 ( 27 to $37^{\circ} \mathrm{N}$, $\sim 10 \mathrm{~km}$ alongshore resolution; D. Glantz, ISP Alginates \& D. Reed, Santa Barbara Coastal LTER, pers. comm.). Infrared images were processed using Arcview GIS (Environmental Systems Research Institute) to map and measure the area of kelp canopies as described by Veisze et al. (2001). The region examined corresponds to the entire biogeographic range of the dominant canopy-forming kelp species Macrocytis pyrifera, and overlaps in the northern portion with 2 other major canopy-forming kelp species, Nereocystis luetkeana and Macrocystis integrifolia (Edwards \& HernándezCarmona 2005). These species cannot be distinguished at the resolution of the photographic surveys. We combined digital maps of kelp canopy distribution from the infrared photographic and satellite surveys (1989, 1999, 2000, 2001, and 2002) to create a composite map of kelp forest occurrence along the coast of WNA. This map allowed estimates of long-term total kelp forest canopy area $\left(\mathrm{km}^{2}\right)$ adjacent to each location along the entire coastline (Fig. 1B). Kelp canopy area estimates were then compared with the long-term mean of independent estimates of kelp surface canopy biomass ( 0 to $1 \mathrm{~m}$ depth) made visually from low-flying aircraft by the same trained observer over 133 mo between December 1989 and October 2002 (groundtruthed using ISP Alginates harvest biomass records from 1958 to 2002; D. Glantz pers. comm.). The spatial pattern of surface canopy cover was in good agreement with the long-term mean of biomass estimates over the entire $1400 \mathrm{~km}$ region of overlap (least-squares regression, $\sqrt{ }\left[\right.$ biomass $\left(\right.$ tons $\left.\left.\mathrm{km}^{-1}\right)\right]=9.462 \times \sqrt{ }[$ surface canopy area $\left.\left.\left(\mathrm{km}^{2}\right)\right]+0.399, \mathrm{r}^{2}=0.620, \mathrm{p}<0.0001\right)$, indicating that surface canopy maps from both sources (Infrared photography and Landsat-7 imagery) were reliable indicators of the long-term pattern of benthic macroalgal biomass. Surface canopy biomass represents approximately 60 to $80 \%$ of the biomass of a mature kelp forest (Santa Barbara Coastal LTER unpubl. data). We, therefore, used the more spatially extensive surface canopy cover dataset ( $3000 \mathrm{~km}$ of coastline) as a proxy for kelp biomass in all analyses.

We assessed the spatial structure of 2 indices of topographic forcing of nearshore ocean conditions: coastal anomalies and local sea surface temperature anomalies $(\Delta \mathrm{SST})$. To calculate coastal anomalies, the 1:250 000 World Vector Shoreline (WVS) for our study region (Soluri \& Woodson 1990) was discretized into uniformly spaced $1 \mathrm{~km}$ segments and latitude/longitude coordinates were smoothed with a $600 \mathrm{~km}$ moving-average filter to remove large-scale trends in coastline direction. The minimum residual distance in kilometers from the raw to the smoothed coast was then calculated. This procedure generated a continuous classification of sections of the coastline into embayments and headlands expressed as a vector of negative and positive anomalies, respectively (Fig. 3B). In addition to the coastal anomaly, we analyzed the square of the coastal anomaly, which distinguishes portions of the coast that bend inward or outward (bays or headlands) from those that are relatively uniform. Similarly, $\triangle \mathrm{SST}$ was calculated from $14 \mathrm{yr}$ (1985 to 1999) of 5 d Advanced Very High Resolution Radiometer (AVHRR) SST satellite composites (Casey \& Cornillon 1999) as the difference between the long-term mean SST in each $10 \mathrm{~km}$ pixel adjacent to the coastline and a smoothed SST spatial series obtained with a $600 \mathrm{~km}$ moving-average filter (Fig. 3A). The $\Delta$ SST represents a classification of sections of coastline according to their positive or negative departure from the large-scale spatial SST trend. As for the coastal anomaly, we analyzed both untransformed and squared forms of this index. We chose the $600 \mathrm{~km}$ filter to remove large-scale gradients in SST and coastal orientation, because preliminary analyses indicated that most of the variation in benthic and pelagic producer biomass occurred at much smaller scales. We interpolated all variables to coastline-following coordinates obtained from the WVS. To avoid loss of data at the ends of the domain due to the filtering procedure, we calculated the coastal anomalies and $\Delta \mathrm{SST}$ from spatial records $600 \mathrm{~km}$ longer on
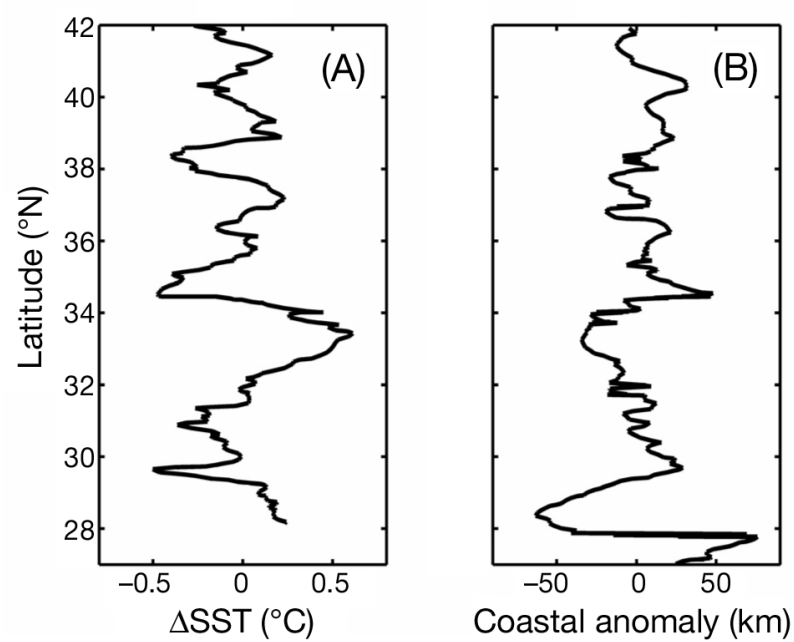

Fig. 3. (A) Local AVHRR (Advanced Very High Resolution Radiometer) sea surface temperature anomaly $(\Delta \mathrm{SST})$ calculated by subtracting the large-scale spatial trend $(600 \mathrm{~km}$ moving average) from the $14 \mathrm{yr}$, long-term mean (1985 to 1999). (B) Coastal anomalies calculated as the departures in kilometers of the raw 1:250 000 World Vector Shoreline from the large-scale trend of the coastline $(600 \mathrm{~km}$ moving average, see 'Materials and methods' for details). The coastline was digitized at a resolution of $1 \mathrm{~km}$ 
each extreme. All datasets were compared at a common resolution $(10 \mathrm{~km})$, equal to the pixel resolution of our coarser SST dataset. Thus, our results are limited to spatial scales larger than twice the resolution of the data $(20 \mathrm{~km})$ (Legendre \& Legendre 1998).

Spatial analysis. Spatial structure was studied using semivariogram analysis, a geostatistical technique. Semivariance is half the variance among all pairs of observations separated by increasing lag distances $(h)$. The relative semivariance, $\gamma(h)$, utilized in the following analyses, is the semivariance at each lag divided by the sample variance. $\gamma(h)$ theoretically fluctuates between 0 and 1, approaching 1 at large $h$ (Deutsch \& Journel 1998). A discontinuity near the origin of the semivariance function, between 0 and the observation at the first lag, is called the 'nugget' and represents the fraction of unresolved small-scale spatial variance. The nugget is regarded as stochastic noise in the spatial process, generally due to measurement errors and microstructures not resolved by the sampling scale. The fraction of semivariance between the nugget and 1 is the 'sill' and represents the proportion of variance that is spatially structured. The distance lag at which the sill is reached corresponds to the characteristic length scale or 'range' of the spatial process and is interpreted as the average patch size in the variable of interest. In practice, the range is approximated as the distance lag at which sample estimates of the relative semivariance become statistically indistinguishable from 1. Excursions of sample estimates of semivariance above the sill are common at larger lags due to 2 features: (1) error of the semivariogram estimates increases rapidly at large lag distances because they are based on fewer pairs of points and (2) adjacent semivariogram estimates are highly autocorrelated due to shared data points. Instabilities beyond the range may also indicate non-stationarity at large scales. Parameters of the underlying theoretical semivariogram can be estimated by a model-fitting procedure that takes these features into account.

To examine similarities in the spatial structure of primary producer biomass, we plotted together semivariograms of kelp cover and chl a. Similarly, the spatial structure of potential forcing mechanisms was examined by plotting together semivariograms of coastline orientation and $\Delta$ SST. The squared versions of the coastal anomaly and $\Delta \mathrm{SST}$ indices were used for this analysis. Spatial structures were objectively compared by fitting spherical models to empirical variograms. The spherical model is a theoretical variogram model in which the semivariance rises smoothly from the first lag to a stable sill at a fixed range (Deutsch \& Journel 1998). Fits were determined using VARFIT, a program that uses weighted, nonlinear, least-squares minimization to estimate the best fit between a theoretical variogram and empirical semivariance estimates. As a weighting function, we used the inverse of the estimation variance of each semivariogram point (Pardo-Iguzquiza 1999). To test the significance of differences in variogram parameters among variables, we repeated the spherical model fit on 10 empirical variograms obtained in moving windows of $600 \mathrm{~km}$ with an overlap of $500 \mathrm{~km}$ between each. This allowed us to obtain a sample of estimates of the variogram range for each variable, which were compared using ANOVA. Because of the overlap between adjacent windows, estimates were not independent, inflating the chance of finding significant differences (high Type I error). Thus, the ANOVA is a conservative test for statistical equivalence of the estimated range parameters (low Type II error).

Semivariogram analysis provides information on the spatial structure of a process, but not the lag separation between 2 variables at which correlation is maximized. Therefore, we also examined the cross-correlation function between benthic and pelagic primary producer biomass at increasing spatial lags up to the maximum scale at which semivariogram analysis revealed spatial structure (Legendre \& Legendre 1998). Cross-correlation analysis allowed us to determine the spatial extent over which benthic and pelagic primary producer biomass exhibited significant covariation, positive or negative. In the present study, negative lag distances are used to denote the poleward (northerly) direction, and positive lags to denote the equatorward (southerly) direction. All analyses were carried out using Matlab 6.5 R13 (The Mathworks) and GSLIB 2.0 (Deutsch \& Journel 1998).

\section{RESULTS}

\section{Spatial patterns of primary producer biomass}

Spatial patterns of chl a and kelp surface canopy cover revealed the existence of considerable heterogeneity in the distribution of benthic and pelagic primary producer standing stock (Fig. 1A,B). Throughout the region, variability in pelagic primary producer biomass was observed both locally and over broad spatial scales. Notable regional peaks of chl a off California loosely coincide with persistent upwelling centers, such as between Cape Blanco and Cape Mendocino $\left(42\right.$ to $\left.40^{\circ} \mathrm{N}\right)$, Point Reyes $\left(38^{\circ} \mathrm{N}\right)$, Point Sur $\left(36^{\circ} \mathrm{N}\right)$, and Point Conception $\left(34.5^{\circ} \mathrm{N}\right)$ (Abbott \& Barksdale 1991, Strub et al. 1991). Several upwelling centers off Baja California del Norte, notably around Punta Colonet $\left(31^{\circ} \mathrm{N}\right)$ and Punta Baja $\left(30^{\circ} \mathrm{N}\right)$, also exhibit increased chl a nearby (Espinosa-Carreon et al. 2004). The spatial pattern of chl a (Fig. 1A) appears less 
variable than the distribution of kelp surface canopy cover (Fig. 1B). Regions of very high kelp abundance (Fig. 1B) are interspersed with regions where surface kelp canopies are not detected by the aerial survey methods employed (resolution 2 to $30 \mathrm{~m}$, see 'Materials and methods'). Large kelp surface canopy cover is evident (Fig. 1B) south of Cape Mendocino, around Point Reyes, between Point Sur and Point Sal $\left(\sim 35^{\circ} \mathrm{N}\right)$, around Point Loma at the US-Mexico border $\left(\sim 32.5^{\circ} \mathrm{N}\right)$ and around Punta Santa Rosalita $\left(\sim 28^{\circ} \mathrm{N}\right)$.

\section{Spatial scales of primary producer biomass}

Semivariogram analysis of benthic and pelagic primary producer standing stock revealed striking similarities in spatial structure across the region examined. In agreement with the general pattern described above, chl a spatial structure is characterized by a small nugget and reaches a sill at a range of $188 \mathrm{~km}$ (Table 1, Fig. 4). The spatial structure of kelp surface canopy cover differs from that of chl $a$ in the large nugget observed (Table 1). This discontinuity at the origin indicates a greater proportion of fine-scale spatial variation in the kelp distribution, as expected from the rougher texture of the kelp spatial pattern seen in Fig. 1A. The spatial structure of kelp cover (Fig. 4) is very similar to that of chl $a$, reaching its sill at a range of about $178 \mathrm{~km}$. These features of the kelp and chl a spatial structure are suggested in the raw spatial patterns (Fig. 1A), but are made clear by the semivariogram analysis (Fig. 4). The excursions of semivariance estimates above the reference line at $\gamma(h)=1$ (Fig. 4) may be attributed to the decreasing number of pairs of points at large distances and the

Table 1. Spherical variogram model parameters fit to empirical variograms from moving windows $(\mathrm{n}=10$, width $=600 \mathrm{~km}$, overlap $=500 \mathrm{~km}$ ) using weighted nonlinear, least-squares minimization (Pardo-Iguzquiza 1999). Standard errors were calculated using $\mathrm{n}=4$, the number of non-overlapping windows in the $2840 \mathrm{~km}$ dataset. Nugget: proportion of unresolved small-scale variance; Sill: fraction of spatially structured variance $($ sill + nugget $=1)$; Range: length scales of the spatial structure, which are not significantly different (ANOVA, $p=0.89, F_{3,36}=0.211$ ). All 10 moving windows were used in the ANOVA to reduce chance of Type II error

\begin{tabular}{|lccc|}
\hline Variable & Nugget (SE) & Sill (SE) & Range (SE) (km) \\
\hline Kelp & $0.35(0.09)$ & $0.65(0.09)$ & $188(100)$ \\
Chl $a$ & $0.13(0.08)$ & $0.87(0.08)$ & $178(34)$ \\
$\Delta$ SST $^{\mathrm{a}}$ & $0.008(0.007)$ & $0.992(0.007)$ & $151(18)$ \\
Coast anomaly & $0.04(0.03)$ & $0.96(0.03)$ & $161(40)$ \\
\multicolumn{5}{c}{$\begin{array}{l}\text { a These variables were } y=x^{2} \\
\text { variance analysis as described in 'Materials and methods' }\end{array}$} \\
\hline
\end{tabular}

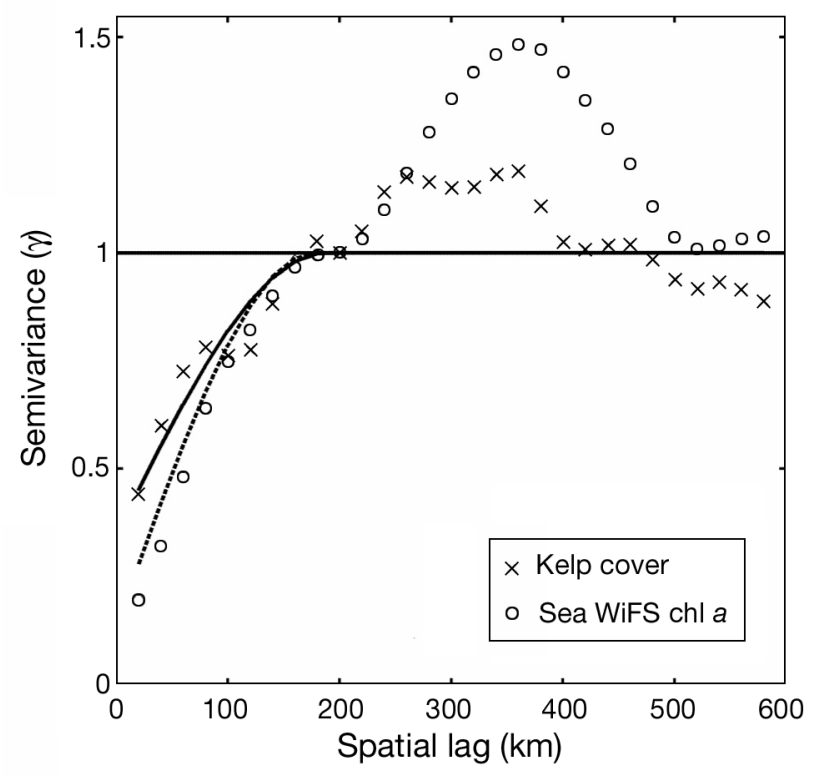

Fig. 4. Semivariance of alongshore SeaWiFS chl a concentration and of kelp (mainly Macrocytis spp.) surface canopy coverage, and fitted model spherical variograms calculated using nonlinear, least-squares minimization (dotted line: chl $a_{\text {; }}$ solid line: kelp). The horizontal line is plotted for reference, and represents the total sample variance. Variograms differ mostly in the discontinuity at the origin, which is indicative of small-scale stochasticity in the kelp cover data (see Table 1 for details of model fits)

non-independence of semivariance estimates at adjacent lags (see 'Materials and methods').

Cross-correlation analysis revealed significant negative correlations of chl a biomass with kelp areal cover extending from $-30 \mathrm{~km}$ to $+150 \mathrm{~km}$ distance lags, with a trough at $+30 \mathrm{~km}(\mathrm{r}=-0.46, \mathrm{p}<0.001$; Fig. 5), indicating reduced chlorophyll concentrations $30 \mathrm{~km}$ equatorward of zones of high kelp abundance. Significant positive correlations were observed between benthic and pelagic biomass at lags similar to and greater than the spatial scales detected by the semivariogram analysis (i.e. $> \pm 180 \mathrm{~km}$ ).

\section{Spatial scales of physical forcing}

Examination of the spatial structure of $\Delta \mathrm{SST}$ (Fig. 6) showed the presence of a sill at approximately $151 \mathrm{~km}$ (Table 1). The coastline of WNA exhibits considerable large-scale patterning in the region examined (Figs. 1C \& 3B), including major regional features, such as the Southern California Bight, and mesoscale features, such as Point Reyes, all of which may influence patterns of nearshore ocean conditions. Length scales of coastal topographic features (bays, headlands) can be quantified 
by examining the extent of coastline sections sharing a common coastal anomaly. Semivariogram analysis of the vector of squared coastal anomalies showed a sill around $161 \mathrm{~km}$ (Table 1, Fig. 6). The length scales of topographic anomalies and $\Delta$ SST were statistically indistinguishable from each other and from the ranges of kelp surface canopy cover and chl a (ANOVA, $\mathrm{p}=0.89, F_{3,36}=0.211$ ). The excursion of semivariance estimates above the reference line at $\gamma(h)=1$ can be attributed to the causes outlined above (see 'Materials and methods').

To determine the spatial dependence of primary producer biomass and $\Delta \mathrm{SST}$ with coastal topography, we examined spatial cross-correlations. The coastal anomaly was significantly correlated with kelp areal cover at short-distance lags $( \pm 20 \mathrm{~km})$, with maximal cross-correlation at Lag $0(r=0.16, p<0.05$; Fig. 7A). A different pattern of spatial dependence was evident between coastline structure and chl $a$. The coastal anomaly was significantly positively correlated with chl a biomass from -20 to $+160 \mathrm{~km}$, with a peak at $+80 \mathrm{~km}(\mathrm{r}=0.33, \mathrm{p}<0.001$; Fig. 7B). Cross-correlations suggested a strong topographic effect on $\Delta \mathrm{SST}$ (Fig. 7C). $\triangle \mathrm{SST}$ was negatively correlated with the coastal anomaly from -150 to $+150 \mathrm{~km}$ lag, with maximum negative correlation at $+30 \mathrm{~km}$ lag $(\mathrm{r}=-0.60, \mathrm{p}<0.001)$. The negative correlation indicated an association between headlands (positive coastal anomaly) and colder-than-average SST (negative $\Delta \mathrm{SST}$ ).

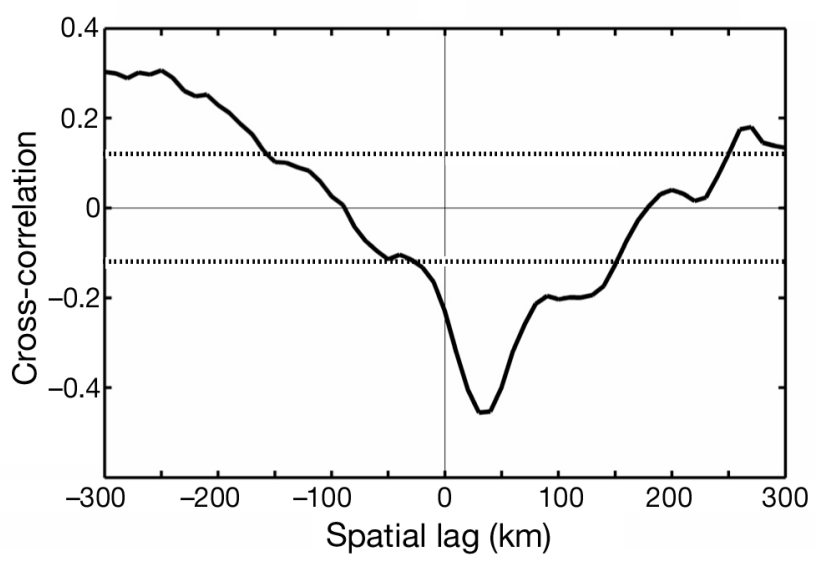

Fig. 5. Spatial cross-correlation between alongshore SeaWiFS chl a concentration and kelp canopy coverage. Correlation at positive lags corresponds to a relationship between chl $a$ and equatorward kelp, while correlation at negative lags corresponds to a relationship between chl $a$ and poleward kelp. Note that correlation is negative for all lags $<50 \mathrm{~km}$ and that kelp and chl a become significantly positively correlated at lags $>150$ to $200 \mathrm{~km}$, both equatorward and poleward. Dotted lines indicate the threshold for significant correlations $(p<0.05)$. Reference lines are plotted at correlation $=$ 0 and $\operatorname{lag}=0$

\section{DISCUSSION}

The results of the present analysis show that primary producer biomass along the coastal upwelling region of WNA is characterized by a complex spatial structure. Patches of primary producer biomass extend over 150 to $200 \mathrm{~km}$, a length scale that is shared with spatial anomalies (i.e. deviations from low-frequency variation) of the coastline and $\Delta \mathrm{SST}$. Patterns of spatial correlation reinforce the hypothesis that the striking match in length scales observed among benthic and pelagic primary producer biomass may be attributed to topographic forcing of nearshore circulation.

Maximal positive cross-correlations between benthic and pelagic producer biomass are found at distances similar to or larger than the characteristic patch scales (>200 km; Fig. 5). These positive correlations at large scales may indicate that the distributions of benthic and pelagic coastal primary producers are offset in space. The hypothesis of a non-overlapping pattern is suggested by the negative correlation of the abundance of chl a biomass with kelp cover in the equatorward direction at lags smaller than the characteristic scale. The cross-correlations of coastline anomalies with kelp cover, chl $a$, and $\Delta$ SST suggest that the tendency for local patches of benthic and pelagic primary producer standing stock to form non-overlapping spatial patterns is driven by topographic forcing of nearshore upwelling and circulation. Coastal anomalies and kelp areal cover present a pattern of spatial dependence that is very similar to that of kelp and chl $a$, although the cross-correlations are of opposite signs (Figs. 5 \& 7A). This indicates that high kelp cover concentrates in the immediate vicinity of positive anomalies of the coastline, such as headlands. Further support for a topographically driven, non-overlapping distribution of primary producer biomass is found in the cross-correlation between coastal anomalies and chl $a$. The coastal anomaly is positively correlated with chl a around $30 \mathrm{~km}$ in the poleward direction, and it peaks $\sim 80 \mathrm{~km}$ in an equatorward ('downstream') direction. The lag distance for maximal cross-correlation of kelp and chl a provides further support for topographic forcing of patchiness in the distribution of primary producer biomass. The negative correlation between chl a and kelp is maximal around 20 to $40 \mathrm{~km}$ in the equatorward direction. $\Delta \mathrm{SST}$ reaches a maximal negative correlation with coastline orientation over similar distance lags, but shows a broader and more symmetric pattern of spatial correlation (Fig. 7C). Taken together, these results suggest that cold water and the associated high nutrient load in the WNA region (Longhurst 1998, Dayton et al. 1999, Blanchette et al. 2006) occur in the vicinity of sections of coastline that show positive anomalies (headlands) over specific length scales. 


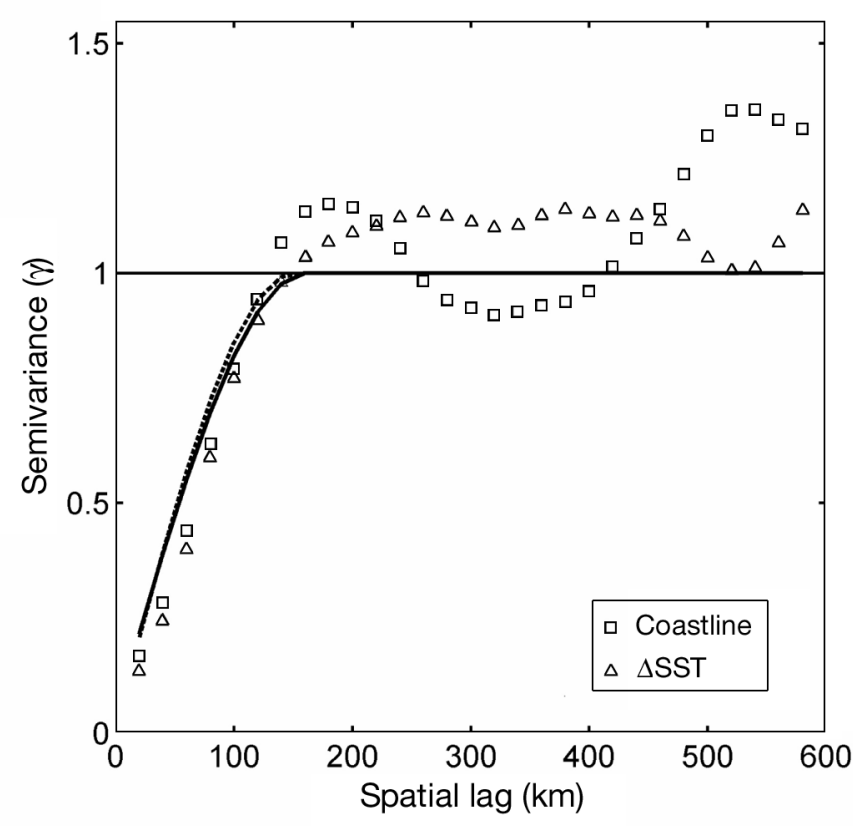

Fig. 6. Semivariance of coastal anomalies and sea surface temperature anomalies $(\triangle \mathrm{SST})$ for the region examined and fitted model spherical variograms calculated using nonlinear least squares minimization (dotted line: $\Delta \mathrm{SST}_{\text {; }}$ solid line: coastal anomaly). The horizontal line is plotted for reference, and represents the total sample variance. Sample variograms are nearly identical in their approach to the sill (see Table 1 for details of model fits). Both data series were $y=x^{2}$ transformed prior to semivariance analysis as described in 'Materials and methods'

These areas present high kelp cover and low nearshore chl a concentration, whereas downstream areas are characterized by lower kelp area and higher phytoplankton biomass.

Large-scale coastal upwelling along the WNA coast is associated to topographic features (e.g. Cape Mendocino, Point Arena, Point Conception) and injects nutrients into coastal waters that are later advected horizontally by circulation processes, stimulating primary productivity across a wide region (Abbott \& Barksdale 1991, Gan \& Allen 2002). Thus, phytoplankton blooms that develop in coastal waters meander offshore and, perhaps, back to coastal waters, usually tens to hundreds of kilometers downstream of major upwelling centers (Strub et al. 1991, Wieters et al. 2003). Large expanses of kelp forest, in contrast, tend to develop in the immediate vicinity of upwelling centers (Fig. 1). During upwelling events, the surface waters become cold and nutrient rich near the shore, while accumulation of phytoplankton is inhibited by the offshore advection of surface waters (Dugdale \& Wilkerson 1989, Abbott \& Barksdale 1991, Strub et al. 1991). The pervasive spatial structure imposed by these circulation processes provides a mechanistic

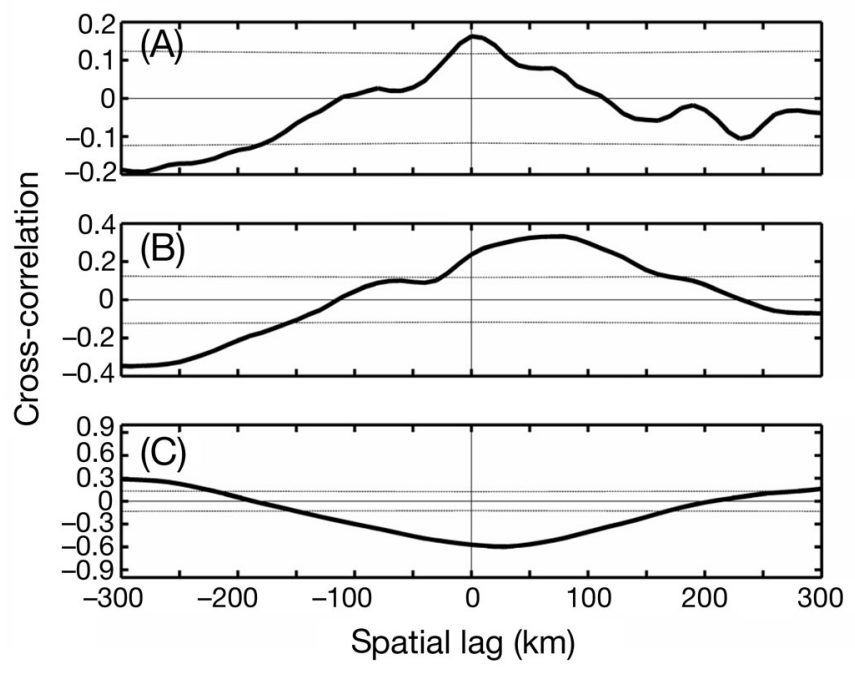

Fig. 7. Spatial cross-correlations between coastal topography (coastal anomalies) and (A) kelp areal cover, (B) chl a concentration, and (C) local $\Delta$ SST. Small-scale positive correlation of kelp cover and coastal anomaly in (A) indicates that higher kelp cover is observed within a narrow $\sim 30 \mathrm{~km}$ area centered around peak positive coastal anomalies, such as capes or headlands. The cross-correlation pattern observed in (B) suggests that chl a concentration is maximal 80 to $100 \mathrm{~km}$ equatorward of positive topographic anomalies. An opposite pattern is observed in (C), where $\Delta \mathrm{SST}$ is negatively correlated to topographic anomalies with almost no spatial lag, indicating the presence of relatively cold water in the vicinity of headlands (positive anomalies) and relatively warm water in the vicinity of embayments (negative anomalies)

explanation for the offset observed in the spatial distribution of kelp inferred through the spatial crosscorrelations.

A number of mechanisms involving the interaction of topography and alongshore flow have been identified (Penven et al. 2000, Gan \& Allen 2002, Roughan et al. $2005 b)$. Our results indicate that a substantial proportion of the spatial variance in kelp forest distribution $(\sim 35 \%)$, and to a lesser extent phytoplankton distribution $(\sim 13 \%)$, occurs at scales below the resolution of our analyses. Flow-coastline interactions at scales below this resolution may play an important role in modifying alongshore flow and may help to explain particular deviations from the large-scale conceptual model outlined above. For example, the kelp forest at Point Loma $\left(\sim 32.4^{\circ} \mathrm{N}\right)$ is the largest in the study region (Fig. 1B,C), yet it is located within the large-scale negative topographic anomaly of the Southern California Bight and experiences warm $\Delta$ SST conditions (Fig. 3). Recent results from this area indicate that topographic divergence of the prevailing southerly flow, and not wind forcing, may cause localized, smallscale upwelling that fuels primary production in the area (Roughan et al. 2005b). In this way, the interaction 
of local topography may strongly influence the spatial distribution of kelp forest stands below the scales resolved by our analysis. Topographically driven mechanisms may also generate spatial patterns in subsurface nutrient delivery in other types of coastal systems, such as passive margins, where large-scale, wind-driven upwelling is not the main driver of coastal circulation. In these coastal ecosystems the spatial scales of primary production are expected to be somewhat smaller than the ones found by our study, as a large part of the physical forcing will originate from topographic forcing of alongshore flow.

The conceptual model presented here relies solely on nutrient delivery as the process driving the distribution of primary producer biomass. This simplified bottom-up view ignores a number of well-documented factors, many of them acting on spatial scales smaller than the resolution of our data that influence the distribution of kelp forests. Benthic macroalgae are usually restricted to shallow rocky reef habitats, where they are vulnerable to dislodgement by physical disturbances, such as wave action and grazing by herbivores (Dayton et al. 1984), and have limited potential for recolonization from distant habitats (Reed et al. 2000). Kelp forest persistence may well be controlled by complex ecological interactions (Estes et al. 1978). These factors may help to explain the greater proportion of small-scale $(<50 \mathrm{~km})$ variability in kelp distribution. Substrate availability and wave exposure are also known to display patterning that is coupled to coastal geomorphology (Longhurst 1998). In areas of high sediment input from coastal watersheds, the availability of hard substrate for attachment of benthic producers is limited by the alongshore transport and progressive accumulation of sediment in littoral cells. Capes and headlands typically bound coastal sediment cells, where sediments accumulate and are exported off the shelf through offshore sinks (Kennett 1982). Similarly, capes and headlands absorb wave energy, predominantly from high-latitude, low-pressure systems, and create areas of low wave exposure in their lee (equatorward). Coastal geomorphology thus influences spatial patterns of disturbance and substrate availability as well as nearshore circulation in the vicinity of capes and headlands.

Because our estimates of kelp canopy area are derived from composite maps of maximum kelp canopy in several years, effects of short-term disturbances will tend to be averaged out. However, local disturbances, substrate availability, and biological interactions have been demonstrated to be major contributors to additional variation in kelp distribution. Unfortunately, consistent, large-scale, high-resolution datasets on nearshore wave exposure and substrate type are not readily available. We were able to locate 1 dataset that continuously classified nearshore subtidal substrates into broad categories of rocky- versus soft-bottom type (Pierson et al. 1987), based on seismic estimates of the depth of Holocene sediment deposition. A spatial analysis on this limited dataset is shown in Fig. 8, where the variogram of kelp cover in the same limited region is overlaid for comparison (see figure legend for details). It is evident that most of the variation in rocky substrate distribution occurs at very small scales $(78 \%$ of variance unexplained by our $20 \mathrm{~km}$ resolution model). This small-scale variation in substrate may directly contribute to the larger nugget effect observed for kelp distribution (35\%; Table 1). Although little additional variance in substrate distribution is explained at larger scales, both spatial processes (substrate and kelp distribution in this limited region) have a remarkably similar range (ca. $120 \mathrm{~km}$ ). This is likely due to the non-random distribution and accumulation of sediment around headlands.

Regardless of the exact nature of the mechanisms maintaining the pattern, the quantitative identification of a common spatial scale of variation in coastal ecosystem

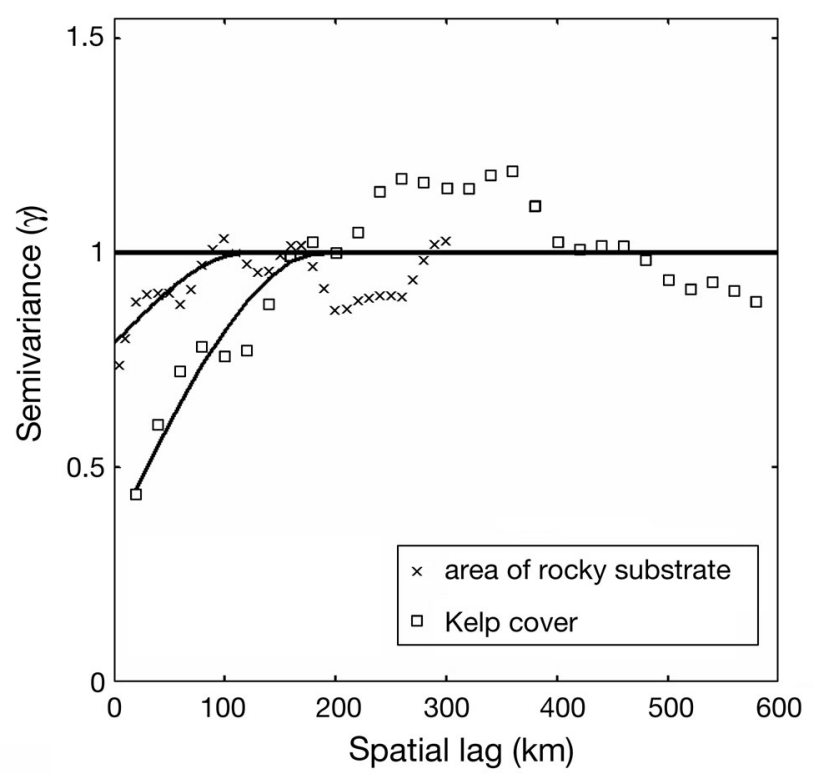

Fig. 8. Semivariance of the approximate area of rocky substrate per kilometer coastline presumed available for kelp colonization (i.e. $>1$ and $<25 \mathrm{~m}$ depth) and of kelp canopy cover per kilometer coastline for a geographic subset of the study region where detailed nearshore substrate maps were available. The region extends from Morro Bay, California, to the US-Mexican border. The horizontal line is plotted for reference, and represents the total sample variance. Fitted model spherical variograms calculated using nonlinear, leastsquares minimization are shown (solid lines). The range, nugget, and sill for substrate area are approximately $120 \mathrm{~km}$, 0.79 and 0.21 , respectively; the same parameters for kelp canopy area are given in Table 1. Substrate data were obtained from Pierson et al. (1987) 
structure has important implications for the ecology, evolution, and management of nearshore communities. The ratio of the scale of dispersal to the scale of environmental heterogeneity is a fundamental parameter in evolutionary and ecological dynamics (Levin 1992). Relative length scales of dispersal and environmental variation affect the outcome of such critical processes as local adaptation (Kirkpatrick \& Barton 1997) and formation of range boundaries (Keitt et al. 2001). At ecological time scales, connectivity due to larval dispersal, perhaps the most critical variable influencing decisions on population management, is highly dependent on the relative magnitudes of dispersal distances, habitat patch size, and distance between patches. For example, Kinlan \& Gaines (2003) found that larvae of most marine fish disperse an average distance of $100 \mathrm{~km}$ or more, whereas invertebrate larvae disperse over a wide range of scales from 10s to 100 s of kilometers, and marine plant propagules move over scales of kilometers or less (Kinlan \& Gaines 2003, Reed et al. 2006). Given the wide range of dispersal potential, our finding that major changes in ecological and oceanographic conditions occur at scales of $\sim 150$ to $200 \mathrm{~km}$ in the WNA ecosystem is especially significant. Most seaweed propagules and some invertebrate larvae, for example, will not easily 'integrate' mesoscale environmental patchiness, because their dispersal scales are far lower than the length scales of important environmental drivers. Accounting for such 'mismatches' in scales of environmental pattern and ecological process will be of profound importance for developing effective spatial management strategies (Airame et al. 2003, Largier 2003).

As the scale of ecological monitoring and experimentation in the nearshore increases, there is growing evidence that a large component of variability in coastal communities is related to oceanographic and geomorphological processes that take place over 10s to 100 s of kilometers. Here, we hypothesize that coastal geomorphology may influence nearshore oceanography and drive alongshore variation in benthic and pelagic primary producer biomass. Our results indicate that the spatial distribution of primary producer biomass in the coastal upwelling system of WNA may be predicted, at least in part, from the spatial structure of the coastline. To test the structuring of coastal primary producer abundance by coastal geomorphology will require very nearshore oceanographic work, coupled with ecological monitoring over appropriate spatial and temporal scales. An important challenge, as ecological experimentation and observation moves to larger scales, is to place local results in the context of larger scale patterns. The largescale spatial distribution of benthic and pelagic primary production may strongly influence benthic community processes at local scales (Bustamante \& Branch 1996, Menge et al. 1997, Navarrete et al. 2005). Thus, increas- ing our ability to predict the distribution and spatial scales of primary producer standing stock based on coastal geomorphology may be useful to the design and implementation of future coastal management and conservation initiatives.

Acknowledgements. We are grateful to S. Gaines, D. Siegel, L. Washburn, C. Blanchette, J. Warrick, P. Kyriakidis, J. Largier, and 3 anonymous reviewers for helpful comments and discussions. We also thank D. Glantz (ISP Alginates) and D. Reed (Santa Barbara Coastal LTER) for providing historical kelp biomass estimates; M. Johnson, D. Bedford, J. Kum, and N. Wright for providing digital kelp canopy maps for California; M. Merrifield and M. Beck for providing digital kelp maps for Baja California and B. Turner for technical assistance with GIS processing. Remote sensing coastal subsets were generously provided by A. C. Thomas for SeaWiFS, and by K. S. Casey for AVHRR composites. The A. W. Mellon Foundation, the Coastal Environmental Quality Initiative (B.R.B.), and a Fannie and John Hertz Foundation Graduate Research Fellowship (B.P.K.) provided financial support. This is Contribution Number 236 from PISCO, the Partnership for Interdisciplinary Studies of Coastal Oceans funded primarily by the Gordon and Betty Moore Foundation and The David and Lucile Packard Foundation.

\section{LITERATURE CITED}

Abbott MR, Barksdale B (1991) Phytoplankton pigment patterns and wind forcing off central California. J Geophys Res C 96:14649-14667

Airame S, Dugan JE, Lafferty KD, Leslie H, McArdle DA, Warner RR (2003) Applying ecological criteria to marine reserve design: a case study from the California Channel Islands. Ecol Appl 13:170-184

Blanchette CA, Broitman BR, Gaines SD (2006) Intertidal community structure and oceanographic patterns around Santa Cruz Island, California, USA. Mar Biol 149:689-701

Brink KH (1983) The near-surface dynamics of coastal upwelling. Prog Oceanogr 12:223-257

Broitman BR, Navarrete SA, Smith F, Gaines SD (2001) Geographic variation of southeastern Pacific intertidal communities. Mar Ecol Prog Ser 224:21-34

Bustamante RH, Branch GM (1996) The dependence of intertidal consumers on kelp-derived organic matter on the west coast of South Africa. J Exp Mar Biol Ecol 196:1-28

Bustamante RH, Branch GM, Eekhout S, Robertson B and 7 others (1995) Gradients of intertidal primary productivity around the coast of South Africa and their relationships with consumer biomass. Oecologia 102:189-201

Casey KS, Cornillon P (1999) A comparison of satellite and in situ-based sea surface temperature climatologies. J Clim 12:1848-1863

Castelao RM, Barth JA (2005) Coastal ocean response to summer upwelling favorable winds in a region of alongshore bottom topography variations off Oregon. J Geophys Res C 110:C10504, DOI:10.1029/2004JC002409

Cipollini P, Cromwell D, Challenor PG, Raffaglio S (2001) Rossby waves detected in global ocean color data. Geophys Res Lett 28:323-326

Dayton PK, Currie V, Gerrodette T, Keller BD, Rosenthal R, Tresca DV (1984) Patch dynamics and stability of some California kelp communities. Ecol Monogr 54:253-289

Dayton PK, Tegner MJ, Edwards PB, Riser KL (1999) Tempo- 
ral and spatial scales of kelp demography: the role of oceanographic climate. Ecol Monogr 69:219-250

Deutsch CV, Journel AG (1998) GSLIB geostatistical software library and user's guide. Oxford University Press, New York

Doney SC, Glover DM, Fuentes M, McCue S (2003) Mesoscale variability of Sea-viewing Wide Field-of-view Sensor (SeaWiFS) satellite ocean color: global patterns and spatial scales. J Geophys Res C 108:C23024. DOI:10.1029/2001JC000843

Dugdale RC, Wilkerson FP (1989) New production in the upwelling center at Point Conception, California: temporal and spatial patterns. Deep-Sea Res I 36:985-1007

Ebert TA, Russell MP (1988) Latitudinal variation in size structure of the west coast purple sea urchin: a correlation with headlands. Limnol Oceanogr 33:286-294

Edwards MS, Hernández-Carmona G (2005) Delayed recovery of giant kelp near its southern range limit in the North Pacific following El Niño. Mar Biol 147:273-279

Espinosa-Carreon LT, Strub PT, Beier EJ, Ocampo-Torres FO, Gaxiola-Castro G (2004) Seasonal and interannual variability of satellite derived chlorophyll pigment, surface height, and temperature off Baja California. J Geophys Res C 109:C03039, DOI:03010.01029/02003JC002105

Estes JA, Smith NS, Palmisano JF (1978) Sea otter predation and community organization in the western Aleutian islands, Alaska. Ecology 59:822-833

Gan J, Allen JS (2002) A modeling study of shelf circulation off northern California in the region of the Coastal Ocean Dynamics Experiment 2. Simulations and comparisons with observations. J Geophys Res C 107:3184, DOI:3110.1029/2001JC001190

Graham WM, Largier JL (1997) Upwelling shadows as nearshore retention sites: the example of northern Monterey Bay. Cont Shelf Res 17:509-532

Kahru M, Mitchell BG (2001) Seasonal and nonseasonal variability of satellite-derived chlorophyll and colored dissolved organic matter concentration in the California Current. J Geophys Res C 106:2517-2530, DOI:10.1029/ 1999JC000094

Keitt TH, Lewis MA, Holt RD (2001) Allee effects, invasion pinning, and species' borders. Am Nat 157:203-216

Kennett JP (1982) Marine geology. Prentice Hall, Englewood Cliffs, NJ

Kinlan BP, Gaines SD (2003) Propagule dispersal in marine and terrestrial environments: a community perspective. Ecology 84:2007-2020

Kirkpatrick M, Barton NH (1997) Evolution of a species' geographic range. Am Nat 150:1-23

Largier JL (2002) Linking oceanography and nearshore ecology: perspectives and challenges. In: Castilla JC, Largier JL (eds) The oceanography and ecology of the nearshore and bays in Chile. Ediciones Universidad Catolica de Chile, Santiago, p 207-239

Largier JL (2003) Considerations in estimating larval dispersal distances from oceanographic data. Ecol Appl 13:71-89

Legendre P, Legendre L (1998) Numerical ecology. Elsevier Science, Amsterdam

Levin SA (1992) The problem of pattern and scale in ecology. Ecology 73:1943-1947

Longhurst A (1998) Ecological geography of the sea. Academic Press, San Diego, CA

McGillicuddy DJ, Robinson AR, Siegel DA, Jannasch HW and 5 others (1998) Influence of mesoscale eddies on new pro- duction in the Sargasso Sea. Nature 394:263-265

Menge BA, Daley BA, Wheeler PA, Dahlhoff E, Sanford E, Strub PT (1997) Benthic-pelagic links and rocky intertidal communities: bottom-up effects on top-down control? Proc Natl Acad Sci USA 94:14530-14535

Navarrete SA, Wieters EA, Broitman BR, Castilla JC (2005) Scales of benthic-pelagic coupling and the intensity of species interactions: from recruitment limitation to top down control. Proc Natl Acad Sci USA 102:18046-18051

Otero MP, Siegel DA (2004) Spatial and temporal characteristics of sediment and phytoplankton blooms in the Santa Barbara Channel. Deep-Sea Res II 51:1129-1149

Pardo-Iguzquiza E (1999) VARFIT: a fortran-77 program for fitting variogram models by weighted least squares. Comput Geosci 25:251-261

Penven P, Roy C, Colin A, Colin de Verdiere A, Largier J (2000) Simulation of a coastal jet retention process using a barotropic model. Oceanol Acta 23:615-634

Pierson LJ, Schiller GI, Slater R (1987) Archaeological resource study: Morro Bay to Mexican border: final report. MMS 87-0025. United States Department of the Interior Minerals Mangement Service, Washington, DC

Reed DC, Raimondi PT, Carr MH, Goldwasser L (2000) The role of dispersal and disturbance in determining spatial heterogeneity in sedentary organisms. Ecology 81: 2011-2026

Reed DC, Kinlan BP, Raimondi PT, Washburn L, Gaylord B, Drake PT (2006) A metapopulation perspective on patch dynamics and connectivity of giant kelp. In: Kritzer JP, Sale PF (eds) Marine metapopulations. Academic Press, San Diego, CA, p 353-386

Roughan M, Mace AJ, Largier JL, Morgan SG, Fischer JL, Carter ML (2005a) Subsurface recirculation and larval retention in the lee of a small headland: a variation on the upwelling shadow theme. J Geophys Res C 110:C10027, DOI:10.1029/2005JC002898,

Roughan M, Terrill EJ, Largier JL, Otero MP (2005b) Observations of divergence and upwelling around Point Loma, California. J Geophys Res C 110:C04011, DOI:10.1029/ 2004JC002662

Siegel DA (2001) The Rossby rototiller. Nature 409:576-577

Soluri EA, Woodson VA (1990) World vector shoreline. Int Hydrogr Rev 67

Strub PT, Kosro PM, Huyer A (1991) The nature of the cold filaments in the California Current System. J Geophys Res C 96:14743-14768

Thomas AC, Carr ME, Strub PT (2001) Chlorophyll variability in eastern boundary currents. Geophys Res Lett 28: 3421-3424

Uz BM, Yoder JA, Osynhny V (2001) Pumping of nutrients to ocean surface waters by the action of propagating planetary waves. Nature 409:597-600

Veisze P, Kilgore A, Lampinen M (2001) Building a California kelp knowledge data base using GIS. Proceedings of the 21st Annual ESRI International User Conference, July 9-13, 2001. Available at: http://gis.esri.com/library/ userconf/proc01/professional/papers/pap900/p900.htm

Wieters EA, Kaplan DM, Navarrete SA, Sotomayor A, Largier J, Nielsen KJ, Veliz F (2003) Alongshore and temporal variability in chlorophyll a concentration in Chilean nearshore waters. Mar Ecol Prog Ser 249:93-105

Wing SR, Largier JL, Botsford LW, Quinn JF (1995) Settlement and transport of benthic invertebrates in an intermittent upwelling region. Limnol Oceanogr 40:316-329

Submitted: August 30, 2005; Accepted: May 1, 2006

Proofs received from author(s): November 23, 2006 